\title{
Hormone Therapy
}

National Cancer Institute

\section{Source}

National Cancer Institute. Hormone Therapy. NCI Thesaurus. Code C15445.

Various treatment modalities that produce the desired therapeutic effect by means of change of hormone/hormones level. 